\title{
Factors of Competencies on Client Project Performance in a Public Transportation Company
}

\author{
Reta Sandra Devina ${ }^{1}$ and Christiono Utomo ${ }^{2}$ \\ ${ }^{1}$ Department of Management Technology, Institut Teknologi Sepuluh Nopember, Surabaya \\ ${ }^{2}$ Department of Civil Engineering, Institut Teknologi Sepuluh Nopember, Surabaya \\ e-mail: retasandrad@gmail.com
}

\begin{abstract}
In terms of producing good performance during company activities, an employee must have an ability/competency to carry out the assigned tasks according to their main tasks and functions. However, in its implementation, not all companies place their employees in their suitable positions/positions that are well-fitted with their capabilities/competencies. In the project client company, there is an allegation that the lack of competencies by their company employees is the cause of delays, poor quality, and the occurrence of disputes during the project cycle which causes the poor performance of a project. This paper reports several competency factors on client employees that affect individual client project performance in $P T$. $K$. The research sample of this study are employees of PT. K. Data collection using a questionnaire, the data on the questionnaire is analyzed using factor analysis. The results of this research resulted in 8 individual competencies that affect the performance of employees of PT. $K$ formed in 2 factors. Factor 1 is a basic competency on individual characteristics consisting of technical/theoretical knowledge, procedural knowledge, willingness to establish good relations, psychomotor skills, job specific skills, tacit knowledge, and understanding of interaction and conflict objectives. In factor 2 of the top-level competence on the development of individuals, there are critical and creative thinking.
\end{abstract}

Keywords — Competency, Analysis Factor, Performance.

\section{INTRODUCTION}

$\mathrm{H}$ UMAN resources are the most important assets in the company. In this case, employees are the executor who performs the activities of managerial and operational activities on a company to achieve its objectives. So that human resources are assets that must be managed and well developed.

In terms of producing good performance during company activities, an employee must have an ability / competency to carry out the assigned tasks according to their main tasks and functions. Regulation on Standardization of Occupational competence is set forth in Minister of Manpower and Transmigration Republic of Indonesia decree no. 5, published in 2012, about standardization system of national work competence. Chapter 1 from the aforementioned decree mentions that the national work competency standardization system is the comprehensive and synergistic standardization components of the national work competency in order to achieve the objectives of that nation-wide standardization effort.
While in chapter 1 the general provisions of article 2 in more detail mention that the national working competency standard of Indonesia, hereinafter abbreviated to SKKNI, is a formulation of work capability covering aspects of knowledge, skills and/or skills and working attitude [1]. In addition to this ministerial act, the regulation on standardization of competence is with the act of Director General of Training and Productivity of Ministry of Manpower and Transmigration of the Republic of Indonesia No. KEP/217/LATTAS/XII/2012. This act is about guidelines on competency mapping procedures in order to provide the standard reference in competency mapping for various sectors or business field as well as effective and efficient development of SKKNI in each sector.

In a project, there are several stakeholders whose participation capability determines the success of a project. Jha and Iyer (2007) mention that the competence of project clients has a significant influence on the three criteria of project performance, i.e. scheduling performance, quality, and absence of disputes. However, in the execution, not all of the company's client projects put employees in a position that corresponds to their ability/competence so that there is a reason that the inconsistency of competency. This incapacity has been the cause of delays, poor quality, and occurrence of disputes during the project cycle which means poor performance of a project. In this study, it discusses employee competence in a public transport project client company.

In this study, it discusses the individual competency factors of employees who affect the individual performance of the project clients so that the competencies can be found most influence and competencies to be developed.

With this research found the competency factors of employees needed by a project client company as the basis of the placement, determination of the recruitment requirements, and the development of the competency of employees, resulting in optimal project performance.

\section{METHOD}

\section{A. Research Concept}

The main concept of this research was to conduct a study about the factors of competence on the performance of employees in the company's client project. The addressed company was one of the public transportation company in Indonesia. Data sampling and data analysis were done by using questionnaire survey and factor analysis respectively. 
The $1^{\text {st }}$ International Conference on Business and Engineering Management (IConBEM)

February $1^{\text {st }} 2020$, Institut Teknologi Sepuluh Nopember, Surabaya, Indonesia

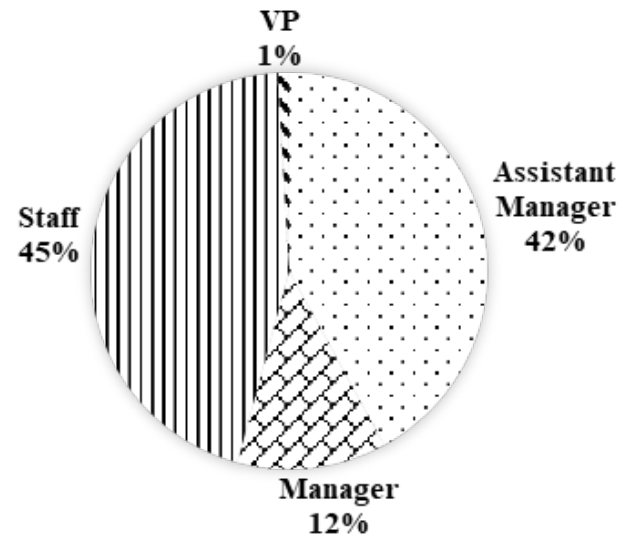

Figure 1. Respondents' profiles based on job title

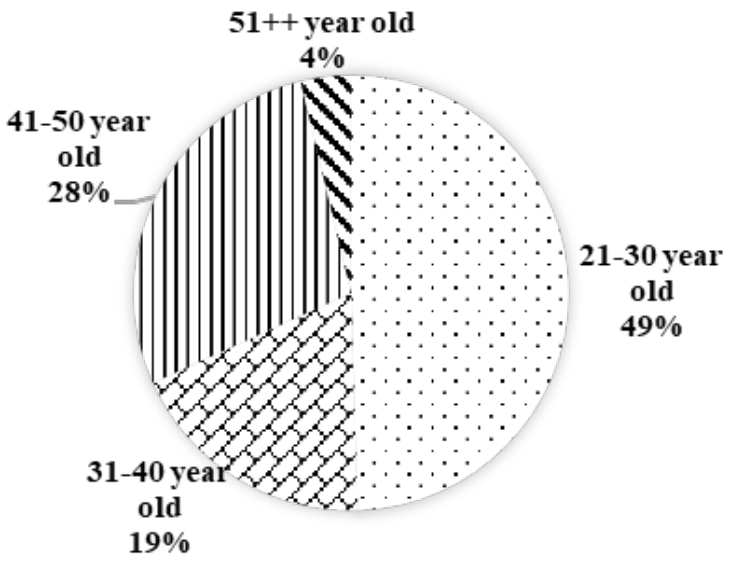

Figure 2. Respondents' profiles based on age

\section{B. Population}

Husaini Usman (2006) expressed the sense of population. According to him, the population is all values of both calculation and measurement, both quantitative and qualitative, from certain characteristics of a complete and clear group of objects. The population of the study is all employees of the company as a client of public transport projects, namely PT. K which is located in the operational area/Regional division. PT. K which is a state-owned enterprise company in the operation of the railway services in Java Island and Sumatra Island.

\section{Sample}

The sample definition according to Nursalam (2003) is a process of selecting portions of the population to represent the population. The sample is the employee of PT. Kereta Api Indonesia (Persero). The sample object in this research is a Building Unit officer in PT. K.

\section{Data Collection Techniques}

The data used in this research is obtained through two sources namely primary data and secondary data. Primary data is data originating from the original source or first source. This data is not available as compiled or in the form of documented files. This data must be obtained through a first-hand resource, in the technical terms a respondent, which means it is the person who we make the object of research or the person we make as a means of obtaining information or data. The primary data referred to in this research is data collected directly from employees who

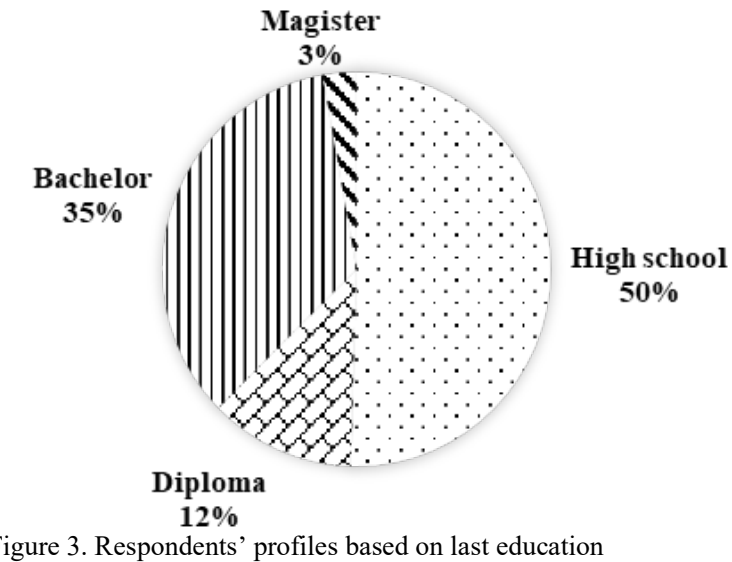

Table 1.

Indicator used for factor analysis

\begin{tabular}{ll}
\hline \hline & \multicolumn{1}{c}{ Indicators } \\
\hline 1 & Tacit knowledge \\
3 & Technical/theoretical \\
4 & Procedural \\
5 & Occupation-specific \\
6 & Psychomotor \\
7 & Ability to shape relationships \\
8 & Understand benefits and tensions \\
9 & Interact professionally \\
10 & Communication \\
11 & Problem solving \\
12 & Critical and creative thinking \\
\hline \hline
\end{tabular}

occupy the structure of the Building Unit of PT. K as a respondent in this research. Primary data collection techniques in this research were collected using the questionnaire method distributed to respondents of the study. The primary data collection is done by spreading the questionnaire to the employees of the headquarter and regional operations unit in Java and Sumatra.

\section{E. Questionnaire Design}

The questionnaire format transmitted to the respondent is based on variables along with the measurement indicators of the pre-defined research variables based on the pilot study results and interconnections between the research variables from the previous related researches mentioned in literature review. According to Riduwan and Kuncoro (2012:20), the Likert scale was used to measure the attitudes, opinions and perceptions of a person or a group of societal events or symptoms. According to Chen et al (2015), the number of alternative answers on the most optimal likert scales are five. In this research, these social symptoms have been assigned specifically by researchers, hereinafter referred to as the research variables. Therefore, the chosen measuring instrument in this study is the Likert scale.

\section{F. Factor Analysis}

The type of research method is factor analysis. The analysis of the factors in principle is used to reduce data, which is the process to summarize a number of variables to fewer and name them as factors [2]. 
The $1^{\text {st }}$ International Conference on Business and Engineering Management (IConBEM)

February $1^{\text {st }} 2020$, Institut Teknologi Sepuluh Nopember, Surabaya, Indonesia

Table 2.

KMO and Barlett's test

\begin{tabular}{ccc}
\hline \hline Kaiser-Meyer-Olkin Measure of Sampling Adequacy & 0,892 \\
\hline & Approx. Chi & 349,361 \\
Barlett's Test of Sphericity & Square & 28 \\
& df & 0,000 \\
\hline \hline
\end{tabular}

Table 3.

Anti-Image Matrices

\begin{tabular}{lc}
\hline \multicolumn{1}{c}{ Indicators } & MSA \\
\hline Tacit knowledge & $.921^{\mathrm{a}}$ \\
Technical/theoretical & $.863^{\mathrm{a}}$ \\
Procedural & $.882^{\mathrm{a}}$ \\
Occupation-specific & $.932^{\mathrm{a}}$ \\
Psychomotor & $.915^{\mathrm{a}}$ \\
Ability to shape relationships & $.896^{\mathrm{a}}$ \\
Understand benefits and tensions & $.873^{\mathrm{a}}$ \\
Critical and creative thinking & $.780^{\mathrm{a}}$ \\
\hline \hline
\end{tabular}

\section{G. Identify Correlation Between Indicators}

Kaiser-Meyer-Olkin (KMO), which is an index comparing the magnitude of the correlation coefficient observed by the magnitude of a partial coefficient. The resulting number must be greater than 0,50 so that the factor analysis can be further processed. Bartlett's Test of Sphericity is a test that is used to test interdependencies between variables that are the indicator of a factor. This analysis intends to declare that the variables in question are not correlated with one another in the population with a significance of less than 0,05 [2].

\section{H. Identifying Data Adequacy}

If the MSA number is a variable below 0,5 then the variable must be issued and also repeated variable selection [2].

\section{Extraction Factors}

Communalities test is a test that shows how large the diversity of original variables are. It can explain at least 50\% of the diversity of origin variable data. The greater the value on the table of communalities the more closely the relationship between the indicators studied with the factors formed [2].

\section{J. Determining Number of Factors}

It is the test that shows the number of variants associated with each factor. Factors that have a value of more than 1 eigenvalue can be inserted into the model, whereas if there is a value of less than 1 is a factor that can not be put into the model [2].

\section{K. Rotation Factor}

Component Matrix shows the coefficient that used to declare a standard variable called a factor. The coefficient of loading factor indicates the correlation between origin variables and factors. A large correlation value expresses a close connection between the original factors and variables so that variables can be created to form factors. A complex matrix is very difficult to interpret the factor. Therefore, the rotational factor is used. In the rotation of the matrix factor transformed into a simpler form making it easier to interpret.
Table 4. Communalities

\begin{tabular}{lcc}
\hline \hline & Initial & Extraction \\
\hline Tacit knowledge & 1.000 & 0.557 \\
Technical/theoretical & 1.000 & 0.715 \\
Procedural & 1.000 & 0.713 \\
Occupation-specific & 1.000 & 0.551 \\
Psychomotor & 1.000 & 0.641 \\
Ability to shape relationships & 1.000 & 0.667 \\
Understand benefits and tensions & 1.000 & 0.562 \\
Critical and creative thinking & 1.000 & 0.851 \\
\hline \hline
\end{tabular}

Table 5.

Total Variance Explained

\begin{tabular}{cccc}
\hline \hline Faktor & Eigenvalue & \% of Variance & Cumulative \% \\
\hline 1 & 4.223 & 52.783 & 52.783 \\
2 & 1.033 & 12.919 & 65.702 \\
\hline \hline
\end{tabular}

Rotated component matrix shows the distribution of variables that have been extracted into a factor that has been formed based on the loading factor after the rotation process [2].

\section{RESULTS AND DISCUSSION}

\section{A. Research Respondent Profiles}

Based on the questionnaire collected from the respondent, the profile was obtained by respondents, consisting of the job title of respondents, the age of respondents, and the latest education. The questionnaire was distributed to 144 employees, while accumulated as many as 107 employees as respondents.

1) Respondents' profiles based on job title

Based on the data of the respondents collected based on their position, most of the respondents held the position as staff/executor of $45 \%$, subsequent assistant manager position of $42 \%$, manager of $12 \%$, and vice president/VP of $1 \%$ of the entire respondent.

2) Respondents' profiles based on age

Based on the data of respondents accumulated by age, most of the respondents were $21-30$ years old i.e. $49 \%$, The age of $41-50$ is $28 \%$, the age of $31-40$ is $19 \%$, and the age of 51 years and above is $4 \%$ of the total respondents.

3) Respondents' profiles based on last education

Based on the data of respondents gathered based on the last education, most respondents had a high school education/SMK of $50 \%$, further undergraduate education of $35 \%$, diploma education of $12 \%$, and master's degree in $3 \%$ of the entire respondent.

\section{B. Analysis of Research Data}

Based on the questionnaire collected from respondents, the analysis of the data is factor analysis. The indicators used in the study is shown in Table 1.

In the testing factor analysis of 12 indicators, there are 4 indicators that do not pass the test KMO, Bartlett Test, MSA, and Communalities. Obtained 2 variants of factor types from 8 indicators because it has a value of eigenvalue greater than 1. 
The $1^{\text {st }}$ International Conference on Business and Engineering Management (IConBEM)

February $1^{\text {st }} 2020$, Institut Teknologi Sepuluh Nopember, Surabaya, Indonesia

Table 6.

Rotated Component Matrix

\begin{tabular}{lcc}
\hline \hline & \multicolumn{2}{c}{ Component } \\
\cline { 2 - 3 } & $\mathbf{1}$ & $\mathbf{2}$ \\
\hline Technical/theoretical & $\mathbf{0 , 8 4 5}$ & $-0,008$ \\
Procedural & $\mathbf{0 , 8 4 3}$ & $-0,053$ \\
Ability to shape relationships & $\mathbf{0 , 7 4 6}$ & 0,331 \\
Psychomotor & $\mathbf{0 , 7 3 0}$ & 0,330 \\
Occupation-specific & $\mathbf{0 , 7 1 6}$ & 0,195 \\
Tacit knowledge & $\mathbf{0 , 6 6 2}$ & 0,345 \\
Understand benefits and tensions & $\mathbf{0 , 5 5 6}$ & 0,503 \\
Critical and creative thinking & 0,027 & $\mathbf{0 , 9 2 2}$ \\
\hline \hline
\end{tabular}

\section{Identify Correlation Between Indicator}

From the Table 2, the results showed by Bartlett's Test of Sphericity was 349,361 with a significance of 0.000 which means it qualifies because of the significance below 0,05 $(5 \%)$ and shows that between the variables correlation occurs.

\section{Identifying Data Adequacy}

In the anti-image matrices table (see Table 3), if the MSA value is greater than 0.75 then the variable is already eligible for further analysis. It can be seen that the 8 variables of the entire indicator have an MSA value of more than 0.75 . So it can be concluded that the variables can be analyzed further.

\section{E. Extraction Factors}

In the communality table, the examined indicators yield a value greater than 0,5 (see Table 4). This indicates that the factors formed have described a $50 \%$ diversity in the origin variable data.

\section{F. Determining Number of Factors}

In the table the total variants can be seen there are two factors that are formed (see Table 5). These two factor are qualified because it has a value greater than 1 . The total variant of both factors is $65.702 \%$ so that it qualifies for a total variant adequacy of $60 \%$.

\section{G. Rotation Factor}

In the table rotated component matrix, factor no. 1 that formed has a correlation with all 7 indicators while factor no. 2 only has a correlation with 1 indicator (see Table 6). The resulting loading factor value is greater than 0,5 so it has a high correlation to the factor.

\section{H. Competency factors affecting performance}

In this research, after analysis of the third factor, it appeared 8 individual competencies that affect the performance of employees of public transportation companies grouped in 2 factors. Factor 1 consists of technical/theoretical knowledge, procedural knowledge, willingness to establish good relationships, psychomotor skills, job-specific skills, tacit knowledge, and understanding of interaction and conflict objectives. While in Factor 2, there is critical and creative thinking factor.

The individual competencies found in factor 1, according to Sergis and Sampson (2014), are factors formed based on
Table 7.

Competency Factors

\begin{tabular}{lc}
\hline \hline Factor & Indicators \\
\hline Factor 1 & Technical/theoretical \\
& Procedural \\
& Ability to shape relationships \\
& Psychomotor \\
& Occupation-specific \\
& Tacit knowledge \\
& Understand benefits and tensions \\
Factor 2 & Critical and creative thinking \\
\hline \hline
\end{tabular}

individual characteristics. The individual characteristics are a factor of competency that exists on the basis of individual employees at a company [3]. In Factor 2, it is formed from the indicators of critical and fragmentary thinking is the toplevel competency factor that is the development of basic competencies. These competencies contribute to achieving the highest yield in a professional activity. This competence has the ability to learn and easy to adapt to new challenges [4].

\section{CONCLUSION}

Based on the results of research conducted on 107 respondents, it can be concluded that the competency factors affecting the performance of project clients in public transportation companies consist of 2 factors. Factor 1 includes technical/theoretical knowledge, procedural knowledge, willingness to establish good relationships, psychomotor skills, job-specific skills, tacit knowledge, understanding of interaction objectives and conflict. While on factor 2 , it consists of the ability to think critically and creatively.

The individual competencies found in factor 1 are factors formed based on individual characteristics. These individual characteristics are a factor of competency that exists on the basis of individual employees at a company. In Factor 2, it is a factor formed from the development of basic competencies that exist based on individual characteristics. These competencies contribute to achieving the highest yield in a professional activity.

\section{REFERENCES}

[1] I. A. O. Martini, I. K. Rahyuda, D. K. Sintaasih, and P. S. Piartrini, "The influence of competency on employee performance through organizational commitment dimension," IOSR J. Bus. Manag., vol. 20, no. 2, pp. 29-37, 2018.

[2] S. Santoso, Aplikasi SPSS pada Statistik Multivariat. Jakarta: Elex Media Komputindo, 2012.

[3] R. Ismail and S. Zainal Abidin, "Impact of workers' competence on their performance in the Malaysian private service sector," Bus. Econ. Horizons, vol. 2, no. 2, pp. 25-36, 2010, doi: 10.15208/beh.2010.14

[4] H. Sobocka-Szczapa, "Competence of a leader - a manager in an organization," in 3rd International Conference on Social, Economic, and Academic Leadership (ICSEAL 2019), 2019, pp. 74-80, doi: 10.2991/icseal-19.2019.14. 